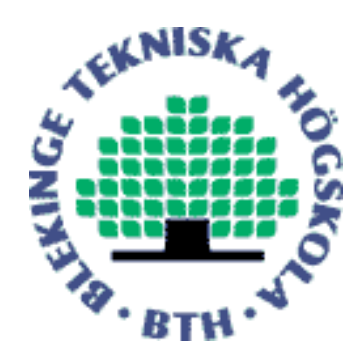

Electronic Research Archive of Blekinge Institute of Technology http://www.bth.se/fou/

This is an author produced version of a paper published in [Journal/ Conference name, date and location]. This paper has been peer-reviewed but may not include the final publisher proof-corrections or journal pagination.

Citation for the published paper: Louise Stjernberg, Johan Berglund, Anders Halling

Age and gender effect on the use of herbal medicine products and food supplements among the elderly Scandinavian Journal of Primary Healht Care, 2006; 24: 50-55

DOI: $10.1080 / 02813430500475522$

Access to the published version may require subscription.

Published with permission from:

Taylor \& Francis 


\title{
Age and gender effect on the use of herbal medicine products and food supplements among elderly
}

\author{
Louise Stjernberg $^{1,2}$, Johan Berglund ${ }^{1,2}$, Anders Halling ${ }^{2}$, \\ ${ }^{1}$ Blekinge Institute for Research and Development, Sweden, \\ ${ }^{2}$ School of Health Science, Blekinge Institute of Technology, Karlskrona, Sweden.
}

\section{Correspondence:}

Louise Stjernberg,

School of Health Science, Blekinge Institute of Technology,

37179 Karlskrona, Sweden,

E-mail: louise.stjernberg@bth.se

Word count:

2265 


\section{Key points}

Herbal medicine products and food supplements are increasingly used throughout the industrialized world.

* In this elderly population almost $30 \%$ were current users and women had a higher probability of being users than men.

* The probability of use decreased with increasing age, $28 \%$ were users in the age group $80-89$ years compared to $14 \%$ in the age group $\geq 90$ years.

* General practitioners need to consider the extensive use of herbal medicine products and food supplements among the elderly when making decisions about treatment. 


\begin{abstract}
Objective. To describe the users of herbal medicine products and food supplements with rregard to age and gender specifically among persons aged $\geq 60$ years. Design. A descriptive study with baseline data from a longitudinal study of the elderly, stratified into different age cohorts $(60-69,70-79,80-89$ and $\geq 90$ years $)$.

Setting. Blekinge county, situated in the southeastern Sweden. Subjects. In total 1380 persons aged 60-96 years (median age 78 years). Main outcome measures. Current use of herbal medicine products and the use of food supplements. Results. Of the participants, 264/1380 (19.1\%) used at least one herbal medicine product, 184/1380 (13.3\%) used at least one food supplement and 382/1380 (27.7\%) used herbal medicine products and/or food supplements. In all regression models, women had a higher probability to use herbal medicine and/or food supplements in comparison with men. Focusing on the use of herbal medicine products alone and in the combination of using herbal medicine and/or food supplement, decreased use was seen with increasing age. However, 27.9\% were still users of herbal medicine products and/or food supplements in the age group 80-89 years. In comparison, $14 \%$ were users in the age group $\geq 90$ years. Age did not have an impact on the probability of taking food supplements.

Conclusion. General practitioners need to consider the high use of herbal medicine product and food supplements among elderly when making decisions about treatment.
\end{abstract}

\title{
Word count: 227
}

Key words: Age, food supplements, gender, herbal medicine 


\section{Introduction}

Herbal medicine products (HMPs) vitamins and minerals (food supplements) are widely used and increasingly prevalent throughout the industrialized world (1-7). Among US citizens a $380 \%$ increase in the use of HMPs and a 130\% increase in the use of high-dose vitamin use were seen between 1990 to 1997 (6). Also in Sweden the prevalence of the use has steadily increased amongst adults during 1980s and 1990s; threefold for the use of HMPs and $70 \%$ for food supplements (8-10).

Among Swedish adults (16-84 years) the use is associated with age, gender, several sociodemographic-, and health behavioural factors (8-12). In comparison with men, females seems to be the more frequent users of food supplements, and among both men and women a high use is seen among the elderly population $(9,10,12)$. In addition, the use of HMPs is higher among women compared with men and an increasing use with increasing age among men has been suggested $(8-10,12)$. The use is described in addition to traditional therapies and is related to high use of health care services $(13,14)$. It is reported to be used independently of conventional medicine and more than half of the users do not discuss their use with their physician $(6,8,14)$. Consideration the potential toxicity of these drugs and to enable evidence based advice, health care professionals need to increase their knowledge of user populations. $(5,15,16)$. Earlier Swedish studies have examined populations within a large age span and not specifically elderly persons (8-12). The aim of this study was to describe the users of HMPs and food supplements, with regard to age and gender, specifically among persons aged $\geq 60$ years in a population based sample in a community in the southeastern part of Sweden. 


\section{Materials and methods}

\section{Study area}

The study was performed within The Swedish National study on Aging and Care (SNAC), an interdisciplinary longitudinal study, which commenced in 2001 (17). This study includes baseline data collected between April 2001 and May 2003 from Karlskrona municipality (with 60600 inhabitants), situated in the southeastern part of Sweden. A random, age stratified sample was selected from the population registry among those aged 60, 66, 72, 78 and 81 years. Among those aged 84, 87, 90, 93 and 96 years the entire population was included. For easier management, the participants were divided into the following age groups; $60-69,70-79,80-89$ and $\geq 90$ years. The elderly received an invitation to participate in the study by post. New contacts, via telephone (three attempts), were made after 2 weeks to those not replying to the first invitation. The participants were invited to the research center and for those unable to come, a home visit was undertaken. Prior to the visit the participants were asked to bring a list or the packaging of prescribed drugs, non-prescribed drugs and used HMPs. To verify the use of current drugs, a research nurse interviewed the participants and filled in the questionnaire answers.

\section{Definitions}

In this study HMPs includes medicinal products in which the active ingredient or ingredients derive from natural sources, have not been processed too extensively and consist of part of a plant or animal, bacterial culture, mineral, salt or salt solution. Also, they are products suitable for self-medication in accordance with tested national tradition 
or tradition in neighbouring countries with respect to drug usage $(18,19)$. According to the manufacturer's description of intended use, HMPs were classified into the following indication groups: cardiovascular, psychiatry, gastrointestinal, musculoskeletal, urogenital and infectious (18). Food supplements includes vitamins and minerals normally found in, and consumed as part of the diet according to the established list from the European Parliament and the Council of the European Union (20). None of the used drugs were prescribed by a physician or other health care practitioners.

\section{Statistical analysis}

Descriptive statistics were computed to evaluate the data for sample characteristics. A Pearson chi-square test was used to test differences in the characteristics between groups and $\mathrm{p}<0.05$ was considered as statistically significant.

Binary logistic regression analysis was used to determine age and gender differences in the use of HMPs and/or food supplements. The statistical significance of the variables was determined using 95\% confidence interval (CI).

The simultaneous relationship among the dependent variable and independent variables were modeled and evaluated by determining odds ratios (ORs). Possible interaction between the independent variables was tested. All analyses were performed using the statistical software package SPSS (Version 13.0).

\section{Ethics}

Ethical permission for the study was obtained from Lund University. Written consent was obtained from all participants. 


\section{Results}

\section{Characteristics of participants}

A total of 2312 individuals were invited to participate in the study. In total, $1402(61 \%)$ of those invited volunteered to participate.

Of the non-participants, 39\% were men and 61\% were women. Unwillingness involved 756/910 (83\%), 92/910 (10\%) considered themselves too sick and 62/910 (7\%) were not possible to contact.

Of the participants, a total of 1380/1402 answered all the questions analysed in this study. The median age among the participants was 78 years (range 60-96) and the age distribution was: $392 / 1380$ (28.4\%), 340/1380 (24.6\%), 524/1380 (38\%) and 124/1380 (9\%) respectively, in age groups: $60-69,70-79,80-89$ and $\geq 90$ years old. Of the participants, 576/1380 (41.7\%) were males and 804/1380 (58.3\%) females.

\section{Use of HMPs and/or food supplement}

In total, 264/1380 (19.1\%) used at least one HMP, 184/1380 (13.3\%) used at least one food supplement, 382/1380 (27.7\%) used HMPs and/or food supplements. The distribution of gender and age among the users is given in table I. Among the users of HMPs and/or food supplement, 21/128 (16\%) men and 45/254 (18\%) women used more than one product simultaneously. Compared with men, women used more food supplements and also HMPs and/or food supplements (Table I). 


\section{Use of HMPs according to indication}

Among the 264 users, 34 participants used more than one HMP. In total, 111/1380

(8.0\%) used HMPs and were classified within the indication group psychiatric-, 74/1380

(5.4\%) cardiovascular-, 38/1380 (2.7\%) infectious-, 34/1380 (2.5\%) musculoskeletal-,

23/1380 (1.7\%) gastrointestinal-, and 18/1380 (1.3\%) urogenital health related

conditions. Women used more HMPs compared with men within the indication groups

musculoskeletal- (Pearson Chi-Square, $\mathrm{p}=0.011$ ) and urogenital related conditions

(Pearson Chi-Square, $\mathrm{p}=0.002$ ). The distribution of used HMPs among the users

according to indication group is shown in Figure I.

\section{Logistic Regression Analysis}

Dependent variables

Three different models were used, with the following dependent variables:

-model 1) whether the participants took herbal medicine or not,

-model 2) whether the participants took food supplements or not

-model 3) whether the participant took HMPs and/or food supplements or not.

Each dependent variable was categorized on a binary scale $(0=$ no and $1=$ yes $)$.

\section{Independent variables}

No significant effect on the outcome was seen testing for interaction between gender and age group and was therefore not included in the model. Hence, independent variables were;

1. $\operatorname{gender}(0=$ men and $1=$ women $)$, 
2. age (stratified into the following groups: $60-69,70-79,80-89$ and $\geq 90$ years, coded as dummy variables).

Gender and age as predictors for taking HMPs and food supplements

In all analysed models the probability of taking HMPs and/or food supplements was significantly higher for women compared with men. In comparison with ages 60-69 years, significantly decreased use with increasing age group was seen in age 80-89 and $\geq 90$ years among those using HMPs alone and in age $\geq 90$ years among those using HMPs and/or food supplements.

Age did not have any impact on the probability of decreased use among those taking food supplements (Table II). 


\section{Discussion}

We found that $1 / 3$ of the elderly used HMPs and/or food supplements. Women had a higher probability of being users in comparison with men. Furthermore, the use decreased with age.

Most other studies have analysed populations' historical use of these products $(1,2,5-8$, $14,21)$. A strength in this study, minimizing risks for recall bias, is the analysis of the present use of HMPs and/or food supplements in a large population including the oldest people in Sweden. Even if the non-participants consisted mainly of women, this study included more women than men, giving only a small risk for bias due to gender differences among the participants. Since the questionnaire was confidentially treated and when necessary, close relatives helping those with difficulties in reporting their personal use, we find the risk for over- or underestimation to be negligible.

A shortcoming, also experienced by others, were the difficulties in comparing the use of HMPs and food supplements with other studies, due to different definitions of these preparations (22). When comparing our results with others, we have endeavoured to find and use definitions in agreement with the definitions used in this study. Sex and age have earlier been shown to be most important factors for the use of HMPs (12). We did not find any significant differences in the use of solely HMPs between men and women. However, other studies from different regions in Swedish report elderly women as higher users of HMPs compared with men $(8-10,12)$.

As shown by others, also the women in this study used more HMPs and/or food supplements than men (almost $1 / 3$ of the women versus $1 / 5$ of the men $(3,8-10,21)$. 
The majority of the alternative medicine users reason that their usage is for prevention or treatment of existing illness (6). One explanation to the gender difference might be that women in general seem to be more observant of their health status. Several studies have found women to be more likely than men to carry out what they believe is health management (23-25).

More than $1 / 3$ of those using HMPs in this study were classified in the indication group psychiatry related conditions. In addition, a study in Italy states that alternative medicines seem to have a complementary role for the elderly with self-perceived psychological symptomatology or depressive disorders (3). The second most common indication, cardiovascular conditions, involved more than a $1 / 4$ of the users. Urinary health related conditions concerned the smallest group of users.

We did not describe concurrent use of prescription medication. However, earlier reports state that elderly users with neuropsychiatry disorders are more highly represented in combining conventional drugs and herbal medicine products (3). In Eisenberg`s study nearly 1 of 5 of those taking any regularly prescribed medications, concurrently used at least one HMP, a high-dose vitamin or both (6).

The use of prescribed pharmaceuticals increases with increasing age but the opposite applies to the use of HMPs (11). The findings that the probability in taking HMPs alone or HMPs and/or food supplements decreased with increasing age are in accordance with a study from US were the users in the age group 60-69 years comprised $21.3 \%$, in age group $70-84$ years $15.3 \%$ and among those $\geq 85$ years $9.1 \%$ (21). We have not found any other studies describing the use of HMPs and food supplements among the oldest population in Sweden (8-12). This fact pinpoints the importance of describing their use 
despite limitations in drawing conclusions since they only represented $9 \%$ of the participants in this study.

We found a significantly decreased use in the age group $\geq 90$ years. This might be due to the extreme aged impairment of daily life and/or are more dependent on those in their surroundings to purchase these products, economical limitations, an extended use of healthcare services and intake of conventional drugs and/or that the product marketing does not reach this population.

Although the use of HMPs decreased with increasing age, between $17.7 \%-30.1 \%$ of the participants in the age groups $<90$ years used at least one HMP and/or food supplements. The total number of users in our study is in alignment with a population-based study in the US where $18.8 \%$ of the adults mentioned their use of natural products (21). However there seem to be an even greater interest in using HMPs in the general population in the UK where $34 \%$ were users (7).

If the use goes unreported there is a risk of interaction when used together with conventional therapies and medicine $(15,16)$. By including this knowledge of the use of HMPs and food supplements on medical school curricula, physicians and health care practitioners would be better equipped to respond to patient enquiries about HMPs and food supplements and thereby fulfilling their role as patient advocates (26). Studies aiming at epidemiological aspects of the use of HMPs and food supplements are few; they usually describe the use of complementary and alternative medicine in a wider perspective leading to difficulties in drawing conclusions of the use of HMPs and food supplements specifically $(1,2,5-7,14,21,27)$. As a complement to earlier Swedish studies, with a similar aim as in our study but mainly performed in other regions, this 
study provides knowledge specifically focusing on an elderly population living in the southeastern part of Sweden (8-12) .

In conclusion, almost $30 \%$ of the participants used HMPs and/or food supplements. The probability of being a user was greater among women than men. We found a decreased probability of using HMPs with increasing age. However, this did not apply to the use of food supplements. General practitioners need to consider the high use of HMPs and food supplements among the elderly when making decisions for treatment thus enabling evidence based advice. 


\section{Acknowledgement}

We thank the Swedish Ministry of Health and Social Affairs, the Blekinge

Institute for Research and Development and the County Council of Blekinge for funding this study. We are grateful to the staff and participants of SNAC-Blekinge for their help and interest in the study. We also thank Wendy Engman for reviewing the English manuscript, Anna Lengstedt for sharing her knowledge on herbal medicine products and Claes Jogreus for help with statistical analysis. 


\section{References}

1. Sherwood P. Patterns of use of complementary health services in the south-west of Western Australia. Aust J Rural Health 2000;8(4):194-200.

2. Kessler RC, Davis RB, Foster DF, Van Rompay MI, Walters EE, Wilkey SA, et al. Long-term trends in the use of complementary and alternative medical therapies in the United States. Ann Intern Med 2001;135(4):262-8.

3. Dello Buono M, Urciuoli O, Marietta P, Padoani W, De Leo D. Alternative medicine in a sample of 655 community-dwelling elderly. J Psychosom Res 2001;50(3):147-54.

4. Kersnik J. Predicitive charachteristics of users of alternative medicine. Schweiz Med Wochenschr 2000;130:390-4.

5. Cook TF, Frighetto L, Marra CA, Jewesson PJ. Patterns of use and patients' attitudes toward complementary medications: a survey of adult general medicine patients at a major Canadian teaching hospital. Can J Clin Pharmacol 2002;9(4):183-9.

6. Eisenberg DM, Davis RB, Ettner SL, Appel S, Wilkey S, Van Rompay M, et al. Trends in alternative medicine use in the United States, 1990-1997: results of a follow-up national survey. Jama 1998;280(18):1569-75.

7. Ernst E, White A. The BBC survey of complementary medicine use in the UK. Complement Ther Med 2000;8(1):32-6.

8. Al-Windi A. Predictors of herbal medicine use in a Swedish health practice. Pharmacoepidemiol Drug Saf 2004;13(7):489-96. 
9. Messerer M, Johansson SE, Wolk A. Use of dietary supplements and natural remedies increased dramatically during the 1990s. J Intern Med 2001;250(2):1606.

10. Nilsson M, Trehn G, Asplund K. Use of complementary and alternative medicine remedies in Sweden. A population-based longitudinal study within the northern Sweden MONICA Project. Multinational Monitoring of Trends and Determinants of Cardiovascular Disease. J Intern Med 2001;250(3):225-33.

11. Al-Windi A, Elmfeldt D, Svardsudd K. The relationship between age, gender, well-being and symptoms, and the use of pharmaceuticals, herbal medicines and self-care products in a Swedish municipality. Eur J Clin Pharmacol 2000;56(4):311-7.

12. Messerer M, Johansson SE, Wolk A. Sociodemographic and health behaviour factors among dietary supplement and natural remedy users. Eur J Clin Nutr 2001;55(12):1104-10.

13. Al-Windi A. Determinants of medicine use in a Swedish primary health care practice population. Pharmacoepidemiol Drug Saf 2005;14(1):47-51.

14. Astin JA, Pelletier KR, Marie A, Haskell WL. Complementary and alternative medicine use among elderly persons: one-year analysis of a Blue Shield Medicare supplement. J Gerontol A Biol Sci Med Sci 2000;55(1):M4-9.

15. Ernst E. Risks of herbal medicinal products. Pharmacoepidemiol Drug Saf 2004;13(11):767-71. 
16. Gold JL, Laxer DA, Dergal JM, Lanctot KL, Rochon PA. Herbal-drug therapy interactions: a focus on dementia. Curr Opin Clin Nutr Metab Care 2001;4(1):2934.

17. Lagergren M, Fratiglioni L, Hallberg IR, Berglund J, Elmstahl S, Hagberg B, et al. A longitudinal study integrating population, care and social services data. The Swedish National study on Aging and Care (SNAC). Aging Clin Exp Res 2004;16(2):158-68.

18. Fänlöf Å, Tunón H. Naturläkemedel 2004. Stockholm: Svensk Egenvård; 2004.

19. Medical products agency. Authorised Natural Remedies as of April 29, 2005. [Web page] 2005 April 29 [cited 2005 June 15]; Available from: http://www.mpa.se/eng/medical_products/natural_remedies/authorised_NR.shtml

20. The European Parlament end the Council of the European Union. Directive 2002/46/EC of the European Parlament and of the Council of 10 june 2002 on the approximation of the laws of the Member States relating to food supplements. Offical Journal of the European Communities [Web page] 2002 July 12 [cited 2005 March 16]; Available from: http://europa.eu.int/eurlex/pri/en/oj/dat/2002/1_183/1_18320020712en00510057.pdf

21. Barnes PM, Powell-Griner E, McFann K, Nahin RL. Complementary and alternative medicine use among adults: United States, 2002. Adv Data 2004(343):1-19.

22. Harris P, Rees R. The prevalence of complementary and alternative medicine use among the general population: a systematic review of the literature. Complement Ther Med 2000;8(2):88-96. 
23. Liang W, Shediac-Rizkallah MC, Celentano DD, Rohde C. A population-based study of age and gender differences in patterns of health-related behaviors. Am J Prev Med 1999;17(1):8-17.

24. Stjernberg L, Berglund J. Tick prevention in a population living in a highly endemic area. Scand J Public Health. 2005. Published on the Internet.

25. Turner C, McClure R. Age and gender differences in risk-taking behaviour as an explanation for high incidence of motor vehicle crashes as a driver in young males. Inj Control Saf Promot 2003;10(3):123-30.

26. Chez RA, Jonas WB, Crawford C. A survey of medical students' opinions about complementary and alternative medicine. Am J Obstet Gynecol 2001;185(3):7547.

27. Hanssen B, Grimsgaard S, Launsø L, Fønnebø V, Falkenberg T, Rasmussen NKr. Use of complementary and alternative medicine in the Scandinavian countries. Scand J Prim Health Care 2005;23:57-62. 
Table I. The distribution of used herbal medicine products and/or food supplements according to gender and age group.

\begin{tabular}{|c|c|c|c|c|}
\hline & $\begin{array}{l}\text { Herbal } \\
\text { medicine } \\
\text { products }\end{array}$ & & $\begin{array}{l}\text { Food } \\
\text { supplements }\end{array}$ & $\begin{array}{l}\text { Herbal } \\
\text { medicine } \\
\text { products } \\
\text { and/or food } \\
\text { supplements }\end{array}$ \\
\hline$(\mathrm{n}=1380)$ & $\mathrm{n}$ & $(\%)$ & (\%) & (\%) \\
\hline
\end{tabular}

\section{Gender}

$\begin{array}{lcccccc}\text { Male } & (\mathrm{n}=576) & 97 & (16.8) & 52 & (9.0) & 128 \\ \text { Female } & (\mathrm{n}=804) & 167 & (20.7) & 132 & (16.4) & 254 \\ \text { p* } & & \begin{array}{c}0.067 \\ \text { n.s. }\end{array} & & 0.000 & & 0.000\end{array}$

Age group (years)

$\begin{array}{lcccccc}60-69 & 91 & (23.2) & 45 & (11.5) & 118 & (30.1) \\ 70-79 & 71 & (20.8) & 45 & (13.2) & 100 & (29.4) \\ 80-89 & 93 & (17.7) & 82 & (15.6) & 146 & (27.9) \\ \geq 90 & 9 & (7.3) & 12 & (9.7) & 18 & (14.5)\end{array}$

\footnotetext{
* Pearson Chisquare
} 


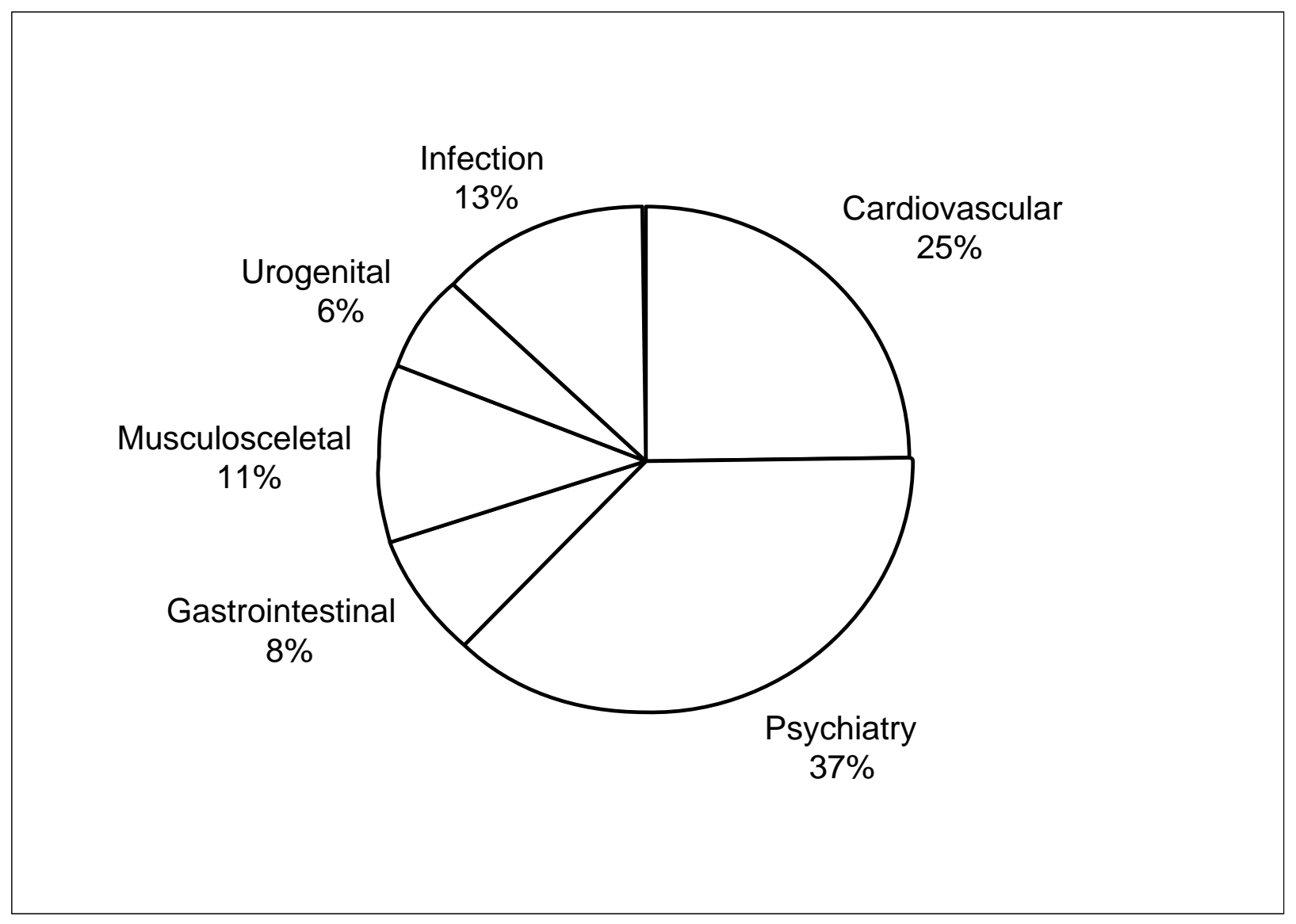

Figure I. The distribution of used herbal medicine product among the users according to indication group. 
Table II. Binary logistic regression predicting independent factors correlated with intake of herbal medicine products and/or food supplements.

Factor Odds ratio Confidence interval P-value

\section{Taking herbal medicine}

\begin{tabular}{|c|c|c|c|c|}
\hline Sex & & 1.382 & $1.045-1.828$ & 0.023 \\
\hline *Age & $70-79$ years & 0.862 & $0.606-1.225$ & 0.407 n.s. \\
\hline & $80-89$ years & 0.694 & $0.501-0.962$ & 0.028 \\
\hline & $\geq 90$ years & 0.253 & $0.118-0.500$ & 0.000 \\
\hline
\end{tabular}

\section{Taking food supplements}

Sex

$1.988 \quad 1.412-2.800 \quad 0.000$

*Age $70-79$ years

1.148

$0.737-1.790$

0.542 n.s.

80-89 years

1.362

$0.920-2.017$

0.123 n.s.

$\geq 90$ years

0,734

$0.373-1.443$

0.370 n.s.

\section{Taking herbal medicine and/or food supplements}

\begin{tabular}{|c|c|c|c|}
\hline Sex & 1.699 & $1.325-2.179$ & 0.000 \\
\hline *Age $70-79$ years & 0.947 & $0.688-1.305$ & 0.740 n.s. \\
\hline $80-89$ years & 0.858 & $0.641-1.148$ & 0.303 n.s. \\
\hline$\geq 90$ years & 0.356 & $0.205-0.615$ & 0.000 \\
\hline
\end{tabular}

* The three age groups were compared with age group 60-69 years 